\title{
20 A Slaughterhouse Pavilion Becomes an Architectural Library in Rome
}

\begin{abstract}
Pavilion 9E is part of a significant industrial archaeological slaughterhouse complex in Rome, dating back to the end of the $19^{\text {th }}$ century. The pavilion closed in 1975, was abandoned and became derelict, with the roof collapsing and leaving the structure in a precarious state. Today, part of the complex has been transformed for use by the Faculty of Architecture of the Università degli Studi Roma Tre/Roma Tre University for its library. The goal of the project was to restore and convert the building for a new public use maintaining a delicate balance between intervention and preservation. The renovation would include both new build additions featuring different elements or materials and restoration of some of the original industrial structures to support the reuse of the building for teaching purposes. The building was given a new roof which maintained the historical characteristics of the former roof; structures were conserved; and the mechanical and electrical plant was updated. The large internal spaces of the ground floor and the mezzanine were divided into various rooms or reconfigured using new furnishings and partitions, to create differently sized and independent spaces.
\end{abstract}

Keywords: Academic libraries - Italy; Library buildings - Design and construction; Industrial archaeology; Slaughtering and slaughter-houses - Remodelling for other use

\section{Introduction}

The Università degli Studi Roma Tre/Roma Tre University with almost 40,000 students is the third university in Rome and one of its characteristics is the reuse of old buildings. Roma Tre University has an overarching Sistema Bibliotecario di Ateneo/university library system, comprising several subject-based libraries including the Biblioteca di Area delle Arti/Fine Arts Library, which has several sections relating to specific faculty or subject areas. One section is the Sezione Architettura "Enrico Mattiello"/Enrico Mattiello Architectural Section or Library, which is the focus of this chapter.

Italy has a huge historic architectural heritage. Any building intervention relating to libraries often involves existing buildings which are under the jurisdiction of the Soprintendenza Speciale di Roma Archeologia Belle Arti e Paesaggio/Superintendent of Fine Arts of the Ministero per i Beni e le Attività Culturali/

Ә Open Access. (C2021 Anna Raimondi, published by De Gruyter. (c) BY-NC-ND This work is licensed under the Creative Commons Attribution-NonCommercial-NoDerivatives 4.0 International License. 


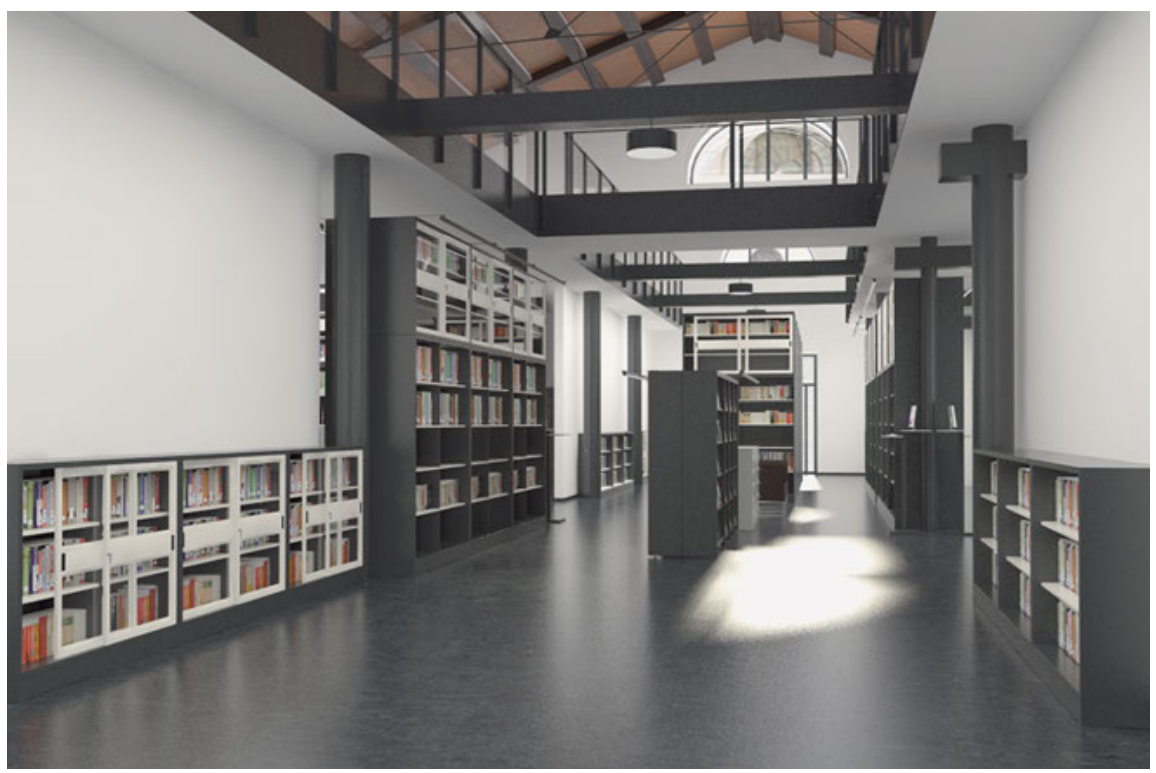

Fig. 1: The new Sezione architettura “Enrico Mattiello". (c) Studio Feiffer \& Raimondi.

\section{Facts and Figures}

Name: Sezione architettura "Enrico Mattiello", Biblioteca di Area delle Arti, Università degli Studi Roma Tre/Enrico Mattiello Architecture Section, Fine Arts Library, Roma Tre University

Address: Largo Giovanni Battista Marzi 10, 00153 Roma RM, Italy Website: https://sba.uniroma3.it/biblioteche/biblioteca-di-area-delle-arti/ Opening: March 2018

Builder: Pasqualucci Costruzioni srl https://www.pasqualuccicostruzioni.it/ Architect: Studio Feiffer \& Raimondi http://www.feiffereraimondi.com/

Gross floor area: $880 \mathrm{~m}^{2}$

Main floor space: $500 \mathrm{~m}^{2}$

Collection size: 20,000

Staff: 5

Workstations: 106

Building Costs: $€ 2,000,000$

Ministry of Cultural Heritage and Activities (MiBAC) and regarded as historic monuments. All requirements relating to the use of a library face restrictions imposed on existing spaces, which often are predetermined and inflexible, and do not support functional changes within a building. Restoring and preserving 
such historic structures and adapting them for reuse as libraries presents two sorts of challenges: the needs and problems linked to the protection of monuments; and the needs and problems linked to the functions of a library.

Key considerations in restoration of buildings that should be considered are the upgrading, renewal and maintenance of structures and electrical and mechanical plants and future library activity. Issues to manage are space, time, regulation and cost. Space and time represent major constraints that require an understanding of how historic buildings work and how they can be converted and adapted most appropriately and cost-effectively. Essential questions when working on a historic structure are: What can I do? What should I do? Time relates to scheduled maintenance and functional management as key elements for the new use and its future development. Any interventions or planned changes to buildings must be specific, sustainable and last for some time.

Architectural projects involving changes to the structure and to use of the facilities must comply with the regulations currently in force. The regulations relate to protection of heritage, structural consolidation, energy embodied in the existing building, public uses, barrier-free access, acoustic and fire insulation and library and museum regulations. Cost is a key consideration. There are the costs of planning but also of restoration, of reinforcing any new build, of upgrading the mechanical and electrical plant, of furnishing as well as management costs and maintenance.

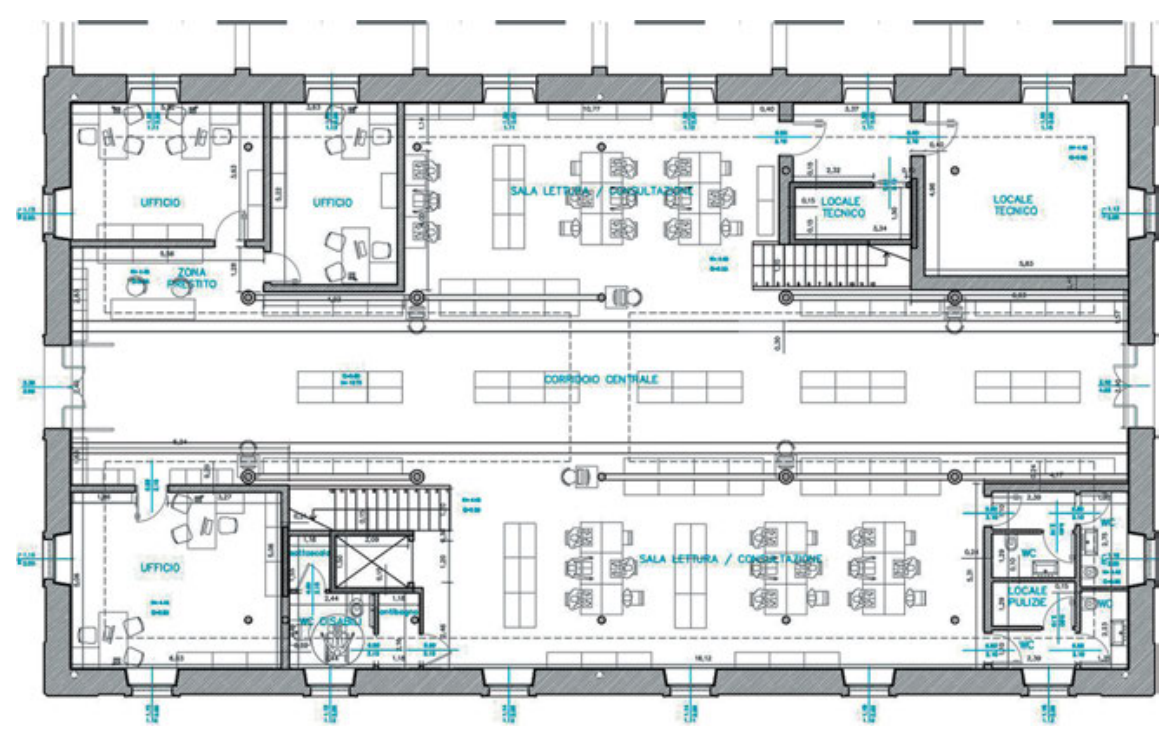

Fig. 2: Ground floor plan with the layout of workstations arranged to solve spatial, functional and technological problems. (C) Studio Feiffer \& Raimondi. 


\section{Pavilion 9E of Mattatoio di Testaccio}

The restoration of Pavilion 9E of the disused slaughterhouse complex in Rome known as Mattatoio di Testaccio (Figure 3) is a clear example of adaptive reuse (Clark 2013). The complex, designed by the architect Gioacchino Ersoch, dates back to the end of the $19^{\text {th }}$ century and constitutes a significant industrial archaeological site. The former slaughterhouse occupies an area of about 25,000 m², surrounding Lungotevere Testaccio and via Beniamino Franklin. The complex is divided into different buildings, pavilions, stores and open spaces, each one with a specific use, perfectly combining design and function.

The slaughterhouse closed in 1975 and development of the site saw part of the complex occupied by the Facoltà di Architettura/Faculty of Architecture of the Roma Tre University (Clark 2013). Some of the buildings house art galleries and temporary festivals and other social and cultural activities but others are still in a state of neglect or have not been completely restored.

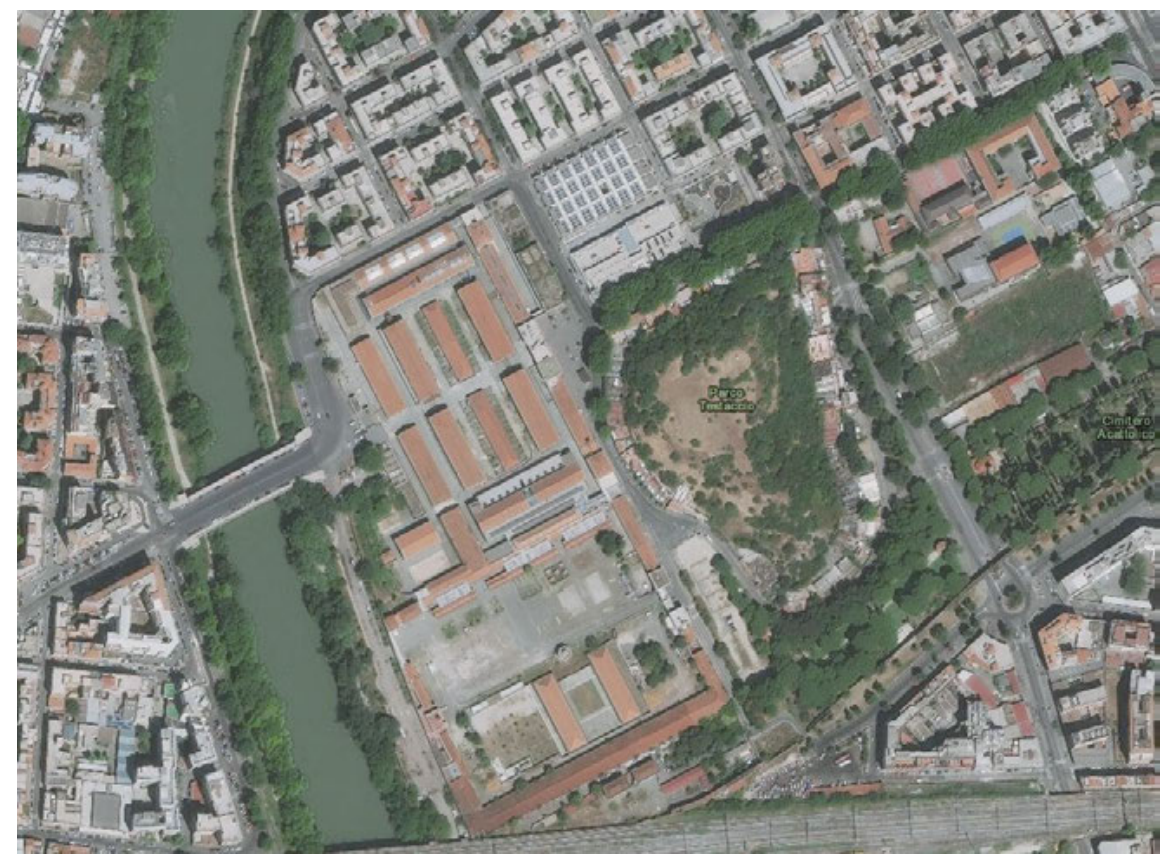

Fig. 3: An aerial view of the Mattatoio di Testaccio complex. (c) Geoportale, Municipality of Rome. 
Pavilion 9E is a medium size building ( $32 \times 18 \times 13 \mathrm{~m}$ ) located in the south of the slaughterhouse complex (Figure 4). It was decided that the architectural section library of the University would be located in it. Until its restoration, Pavilion 9E was derelict; the roof had collapsed, and it was in a precarious structural condition (Figure 5).
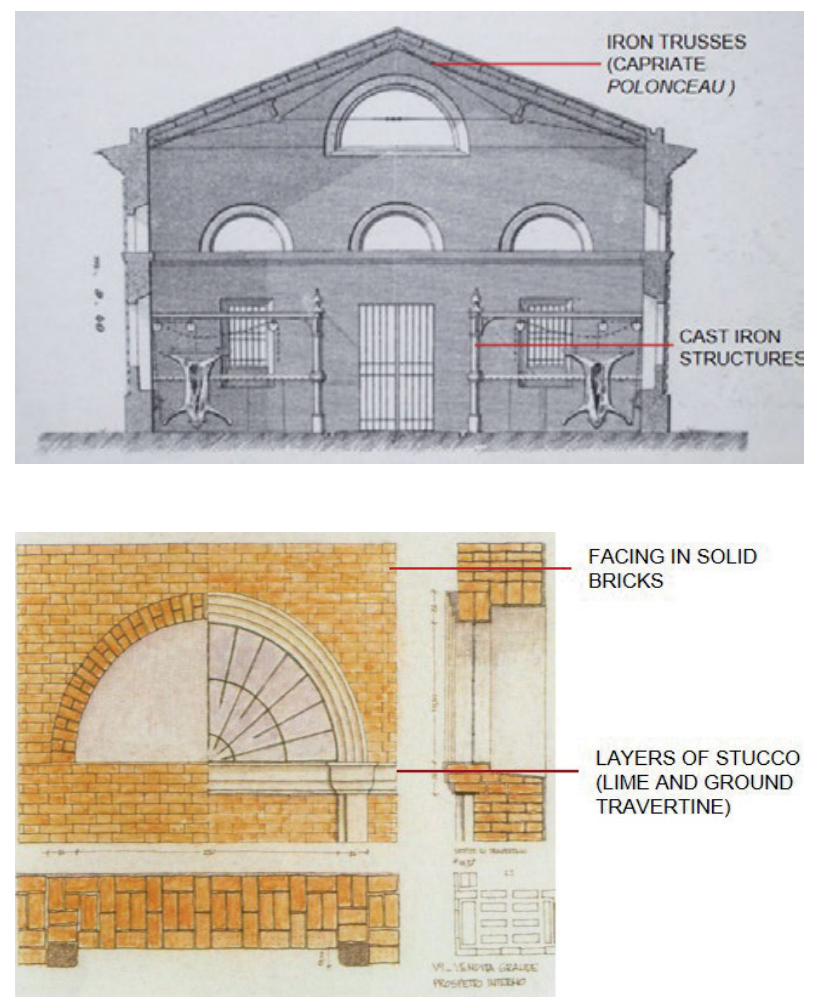

Figs. 4 A and B: Architectural and construction characteristics of Pavilion 9E. (C) Source: Image A: Cuppelloni 2002. Image B: Cremona, Crescentini, Pentiricci, and Ronchetti 2014.

Pavilion 9E has the same architectural and construction characteristics as the other buildings in the complex: a combination of stone and ironwork, bricks and tuff structure, a type of rock made of volcanic ash, with solid bricks and natural hydraulic lime and eco-pozzolan-based mortar, a gable roof supported by iron trusses, façades with a series of regular openings and cornerstones, and ledges coated with layers of stucco with a travertine-like finish (Figure 4). 


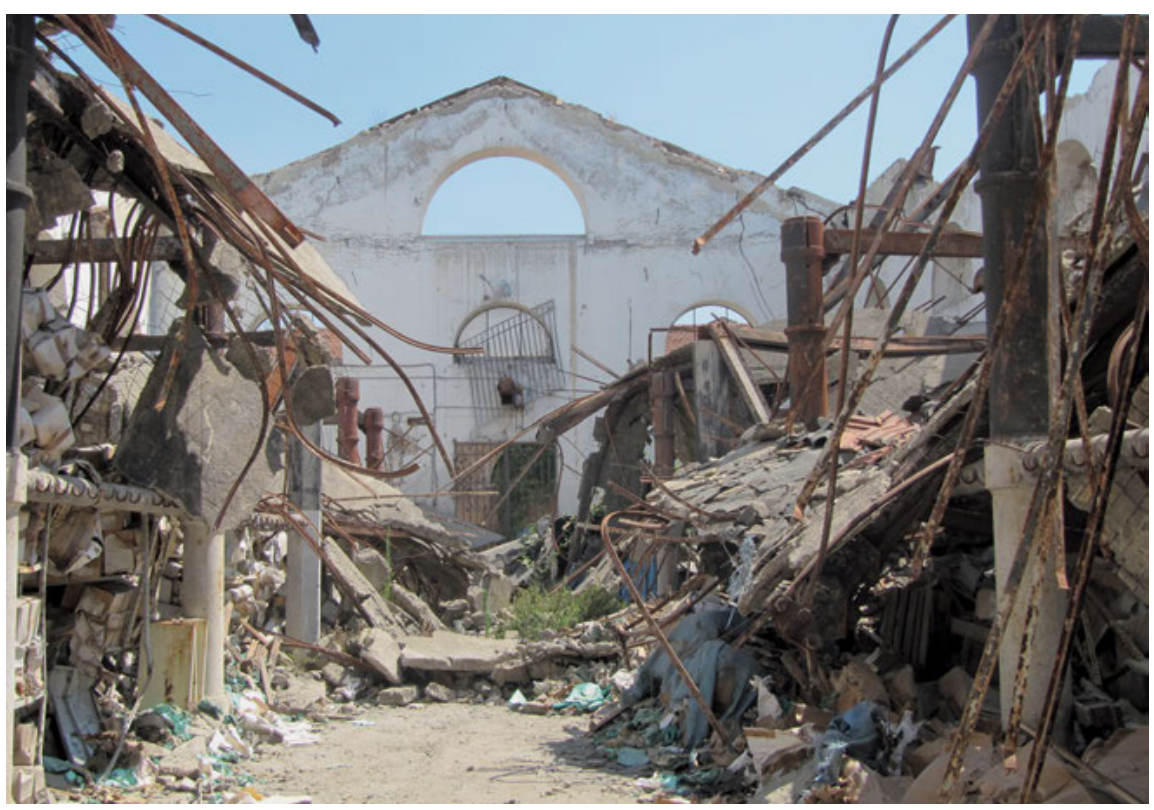

Fig. 5: The Pavilion 9E after the collapse in 2008. (C) Anna Raimondi.

The iron roof structure consisted of primary trusses with secondary purlins between. The trusses had a triangular profile with I-section main rafters, a tension rod lower tie and internal members consisting of struts and ties. Leakage of rainwater and corrosion caused failure of the main ties resulting in collapse of the trusses. As a consequence of the loss of the ties, the external walls, despite their substantial thickness, were incapable of resisting the resulting horizontal thrust from the main rafters and collapsed at the highest levels (Figure 5).

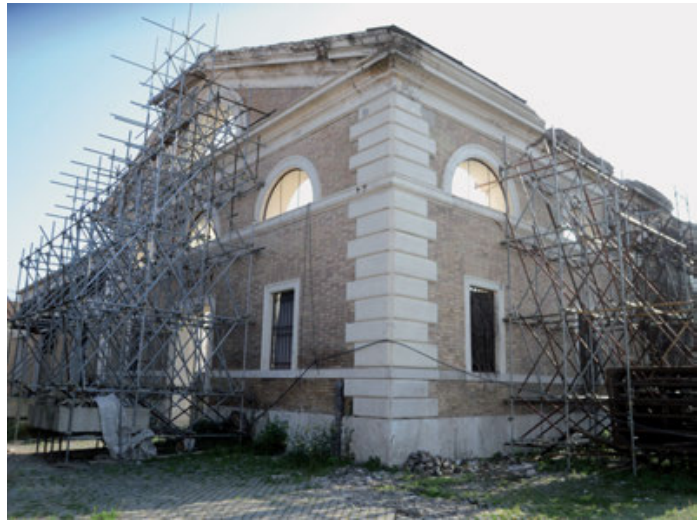

Fig. 6: The temporary constructions to stabilise structures and to ensure safety in the building site. (C) Anna Raimondi. 
Safety on the building site and during the restoration work was of primary importance. In preparing the initial investigation programme, it was necessary to install temporary supports, to stabilise structures and to provide environmental protection (Figure 6). As part of the work, any structural fragments or archival material, such as archaeological and administrative items, were removed and safely stored in cooperation with the appropriate local and national authorities.

After removing roofing and other materials and ensuring the structural walls were stable, the next phase was to measure and study the geometric characteristics of the building, particularly the dimensions of the building as a whole and of component parts including windows, walls and frames to make a diagnosis and plan for restoring the building.

Before starting on the restoration, it was essential to assess the state of the materials used in the building. A team of qualified personnel studied the site using topographic and photogrammetric integrated techniques. It was, therefore, possible to obtain specific building measurements, establish the results of building and structural deformations like displacement of the wall about its vertical axis and to lay the basis for the subsequent reinstatement of the exterior materials.

The vertical walls of Pavilion 9E were unstable because of the loss of part of the peripheral tie and parapet of the southern walls, due to the failure of the iron roof trusses. Finally, a diagnostic analysis of materials and structures was carried out using the following tests:

- Investigation of the materials using thin blades and polished sections

- Geognostic surveys to classify different types of ground level and ground footing which is required to comply with anti-seismic laws

- Ground analysis taking core samples made to a depth of at least 15 m under the surface which identified the water table at $-1 \mathrm{~m}$ under a landfill layer, with a thickness of about $5 \mathrm{~m}$ and for the next 3-8 m, clayish-loamy soil of low and medium compactness, containing organic substances, with quite a low resistance to cut and a high compressibility

- Excavation of wall foundation was carried out to a depth of $3 \mathrm{~m}$ and did not locate the layout or centreline of the foundation

- Ad-hoc flat-jack methods used to obtain the structural modulus of elasticity and break strength parameter, particularly along the east and north façades

- Endoscopy through the wall using a Standard Penetration Test of plasters and chemical and physical analyses. The results provided in-depth information. The walls were made of solid bricks with natural hydraulic lime and eco-pozzolan-based mortar with a ratio of about 1:3; the plaster was classified M25 according to the Ministerial Decree 14 January 2008; the test pressure corresponded to a value ranging from 71 to $110 \mathrm{Mpa}$ and the compressive strength was about $2.5 \mathrm{~N} / \mathrm{m}^{2}$. 
Conservation, reinforcement and restoration of architectural heritage requires a multidisciplinary approach. Work undertaken should be the result of an overall integrated plan that respects the different aspects of architecture, engineering structure, technical systems and functionality. The diagnosis for the Pavilion 9E project was organised in three different fields: architecture and architectural restoration, structural and mechanical and electrical plant, with the following objectives:

- Conservation of materials and archaeological elements of the new postindustrial urban style

- Structural reinforcement of the existing construction

- Interventions to improve stability and seismic retrofitting

- Transformation of spaces for new functions

- Technological adaptation and an improved technical plant system.

\section{Conservation of Materials and Archaeological Elements}

A classification was drawn up with a graphic analysis of the different types of internal and external surfaces in order to identify existing materials with each represented by a specific colour, their state of conservation indicated using a precise pattern for each form of degradation noted and registering the way restoration was to be carried out using symbols calibrated to a graphic key that described the sequence of specific restoration operations. Main actions taken included filling visible gaps in masonry with specific material or mortar, integration of missing elements including bricks, stones and plaster decorations, and conservation of metallic elements of archaeological architecture (Figure 7).

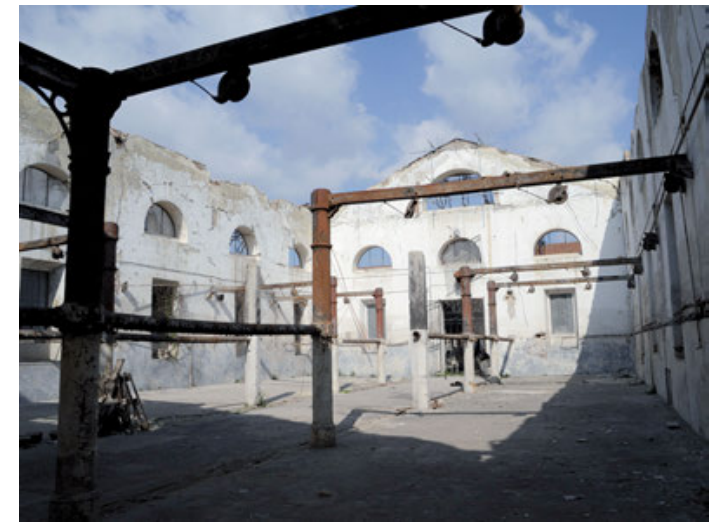

Fig. 7: Typical elements and signs of industrial archaeology that were conserved during the restoration. (c) Anna Raimondi. 
In considering the repair of the structure, two aspects were of primary importance: the use of materials compatible with the original; and good construction techniques to produce a reliable sustainable result.

\section{Structural Reinforcement of the Existing Construction}

\section{The most critical aspects in structural reinforcement were:}

- Reconstruction of the corner elements of the walls using the toothing-out method, cutting back the brickwork in a tooth-like shape into which new bricks are laid, called scuci-cuci. The method allows the adjoining masonry to be made with bricks similar to the original and was chosen because of the state of decay caused by the failure of the rainwater drainage system.

- A complete reconstruction of the gable roof and its supporting structure which was a fresh interpretation of totally damaged structural elements no longer performing their structural role. However, the design of the intervention was based on a historical image and preference was given to work that was the least invasive and most compatible with heritage values. The new roof structure is composed of five steel trusses located between windows, with struts and tie-rods, respectively beams with a HEA240 profile and elements with 40-60 mm in diameter (Figure 8).

- Stability inspection of the basement and footing reinforcement through the construction of a slab of reinforced concrete and continuous footings under new internal walls.

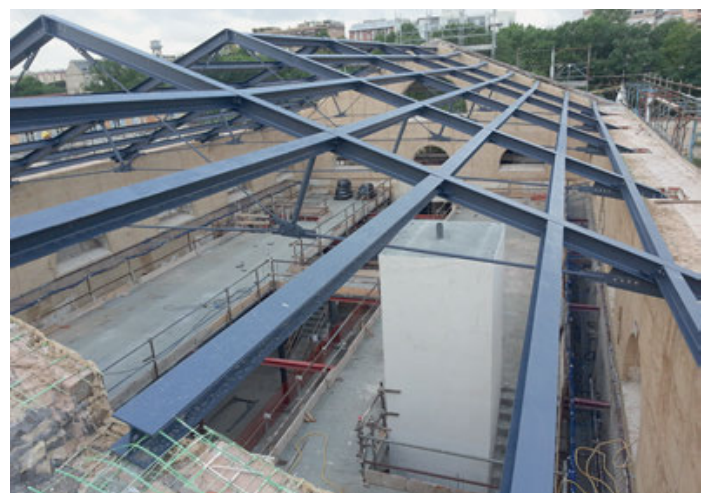

Fig. 8: First phase of the working process for the roof construction, made of steel structures. (c) Cesare Feiffer. 
Improving the building's stability and seismic retrofitting were necessary to contain the horizontal thrusts, adapt the structure to the current anti-seismic regulations and connect transversal and longitudinal vertical partitions. A unique brick stringcourse, reinforced with a fiberglass mesh was created with reinforcing steel bars crossed at the corners, and tie-rods near the new internal floor.

\section{Transformation of Spaces for New Functions}

The aim of the intervention was to respect the concept, techniques and historical value of the original structure and leave evidence of it for the future. Where possible, any measures adopted should be reversible so that any additions could be removed and replaced should new techniques become available. This approach was adopted for all new work required to change Pavilion 9E from a slaughterhouse to a library. The restoration and reintegration of details and features respect the original materials, archaeological evidence, original design and original plans. The reuse project has been mainly influenced by the industrial architectural style of the complex and its archaeological characteristics. The postand-beam construction has defined several new areas, differentiating peripheral areas and corridors from closed areas and offices (Figures 1 and 9).

Inside Pavilion 9E the two levels are now used for library functions, taking advantage of the skeleton construction of the main floor and maintaining an unobstructed view of the central area on the new first floor. The new steel mezzanine is clearly distinguishable, by reference to the expression of architectural and spatial aspects (Figures 10 and 11). The plan of the internal areas has been developed through an interaction with the building, its environment, shape and orientation, defining functional zones and their connections (Figure 2). Restrooms, technical rooms and offices are located on the main level, with reading and consultation rooms on the first level. The spaces are organised as a modular internal volume, structurally independent from the rest of the building. All the new rooms are illuminated by both natural and artificial light, through large rounded arch windows, reaching to the upper floor.

To access the upper level, one can use either a lift or the two flights of stairs, near the central double-height hall. The open elevator shaft is contained within the pavilion, without any external construction. With the addition of the new mezzanine, the internal surface has increased by about $300 \mathrm{~m}^{2}$, from $500 \mathrm{~m}^{2}$ to about $800 \mathrm{~m}^{2}$. 


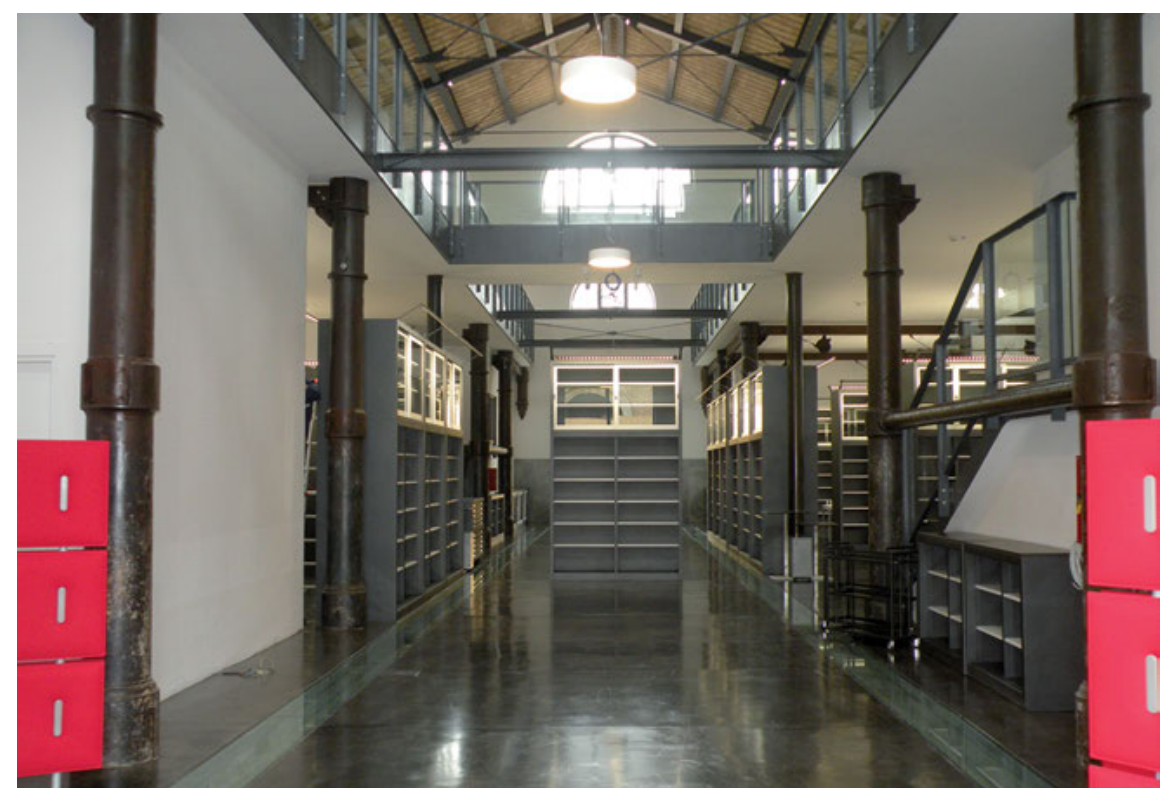

Fig. 9: Internal of the Pavilion 9E after restoration: the roof rebuilt and the iron elements as structures of the new mezzanine. (c) Anna Raimondi.

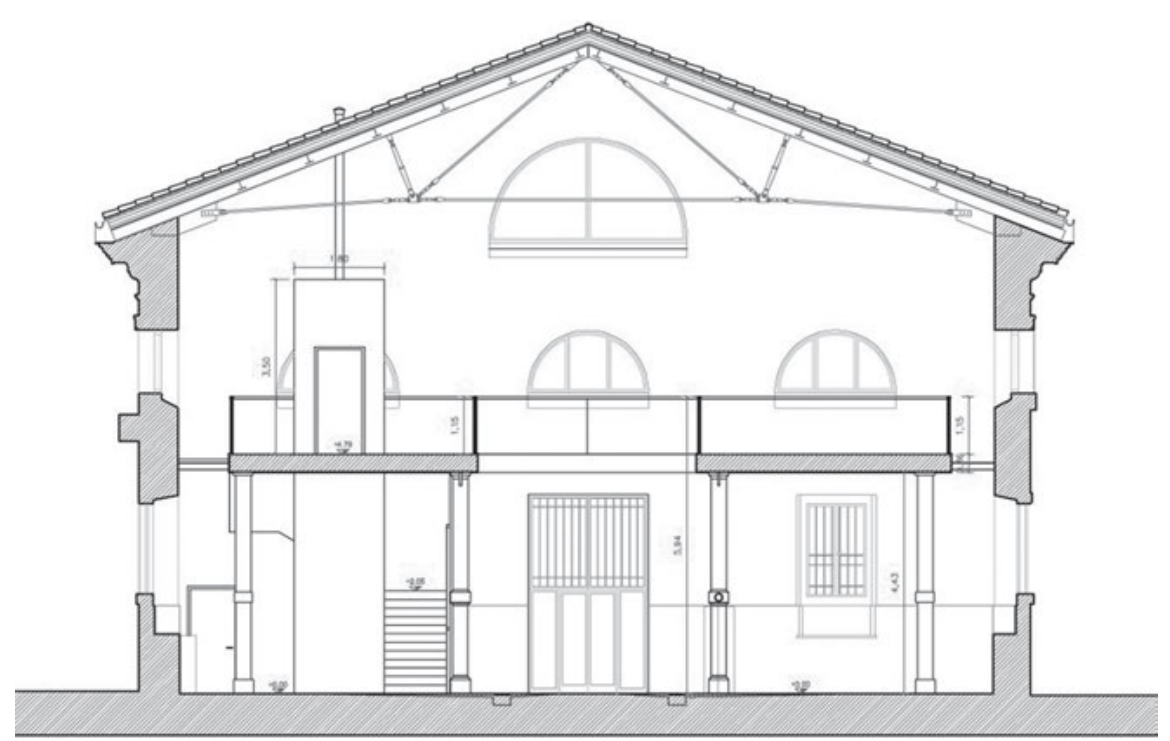

Fig. 10: A transversal section with the drawing of the mezzanine which greatly increases the usable areas. (c) Studio Feiffer \& Raimondi. 


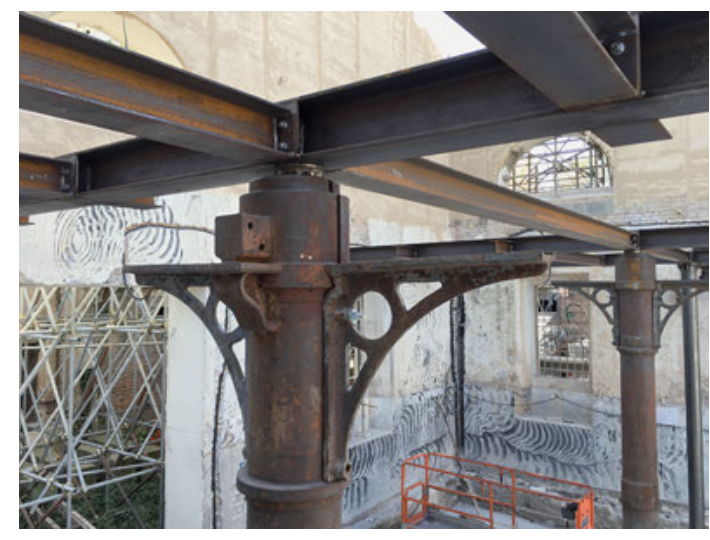

Fig. 11: Structure of the industrial archaeological elements are used as new structural elements for the new mezzanine. (c) Cesare Feiffer.

\section{Technological Modification and the Mechanical/ Electrical Plant System}

A system of service facilities run under the ground floor, using all spaces between the classic Iglù $®$ formworks. To reach the upper levels, the wiring was laid in new technical channels or through new walls. Due to the archaeological restrictions of the pavilion, it was impossible to locate technical equipment underground. The only option was to use a room within the building containing a heat pump that supplies a general electric panel, a system for the required air exchange and several fan coil units both for air conditioning and heating. From this room a distribution of forced ventilation is carried out with visible round pipes, attached under the roof. The technological solution is based on the concept of minimal intervention, reversibility and differentiation. As a library also needs quiet and silent spaces, specialised acoustic technicians studied the acoustic performance of the enclosing walls of the services area.

All power and data supplies and cables are in cavities under the floor and the wiring connects directly to the furniture, to provide functional reading areas and workstations with no loose or trailing cables on the floor (Figures 2 and 12).

\section{The Library Layout}

The entire system of furniture and equipment had to adapt itself to architectonic, structural and technical systems. Therefore, it was necessary to set up an inex- 
pensive means of subdividing the space for particular functions. The furnishings have an important role as they organise the spatial layout of the multi-functional spaces. Several bookshelves, holding approximately 20,000 volumes, are placed between reading areas and fixed workstations. Higher shelving is placed near external walls and the existing cast-iron pillars with lower shelving along the internal passages (Figure 9). This lets in natural light and allows the spatial layout of the building to be clearly visible and perceived as originally intended.

The library includes monographs, essays, books on the history of architecture, science and theory of construction, technology, environmental and urban planning. Since 1995, about 220 issues of major Italian design magazines have been added to the collection. The library has open access shelving, and the books are arranged according to a thematic classification scheme devised by Enrico Matielli that can be easily understood by users (Figure 12). Open access encourages browsing which has benefits although it does not replace rigorous information retrieval methods for specific research.

There are three reading rooms on the ground floor and ten reading areas on the upper level. The library has seating for 106 people, with each study place equipped with electrical connections and multimedia facilities thereby providing perfect workstations for users. As part of the renovation of Pavilion 9E, some abandoned structures of the 1950s and 1960s in the complex were demolished, as they were compromising usability and safety. The demolition of Pavilion 22, on the south side of the library, provided space which could be easily converted into an outdoor extension to the library, with appropriate planting, furnishing and covered structures. The project, with the authorisation of the Soprintendenza Speciale di Roma Archeologia Belle Arti e Paesaggio/Superintendent of Cultural Heritage, respects the vision of the original architect and engineer Gioacchino Ersoch and also the features of the former Mattatoio di Testaccio, considered one of the best examples of industrial archaeology and $19^{\text {th }}$ century civil engineering in Rome. In the future, if economically feasible and taking advantage of funds allocated by Roma Tre University, the works mentioned above will take place which will complete the urban and functional transformation of the whole area, as a place where arts and cultural treasures remain to be discovered. 


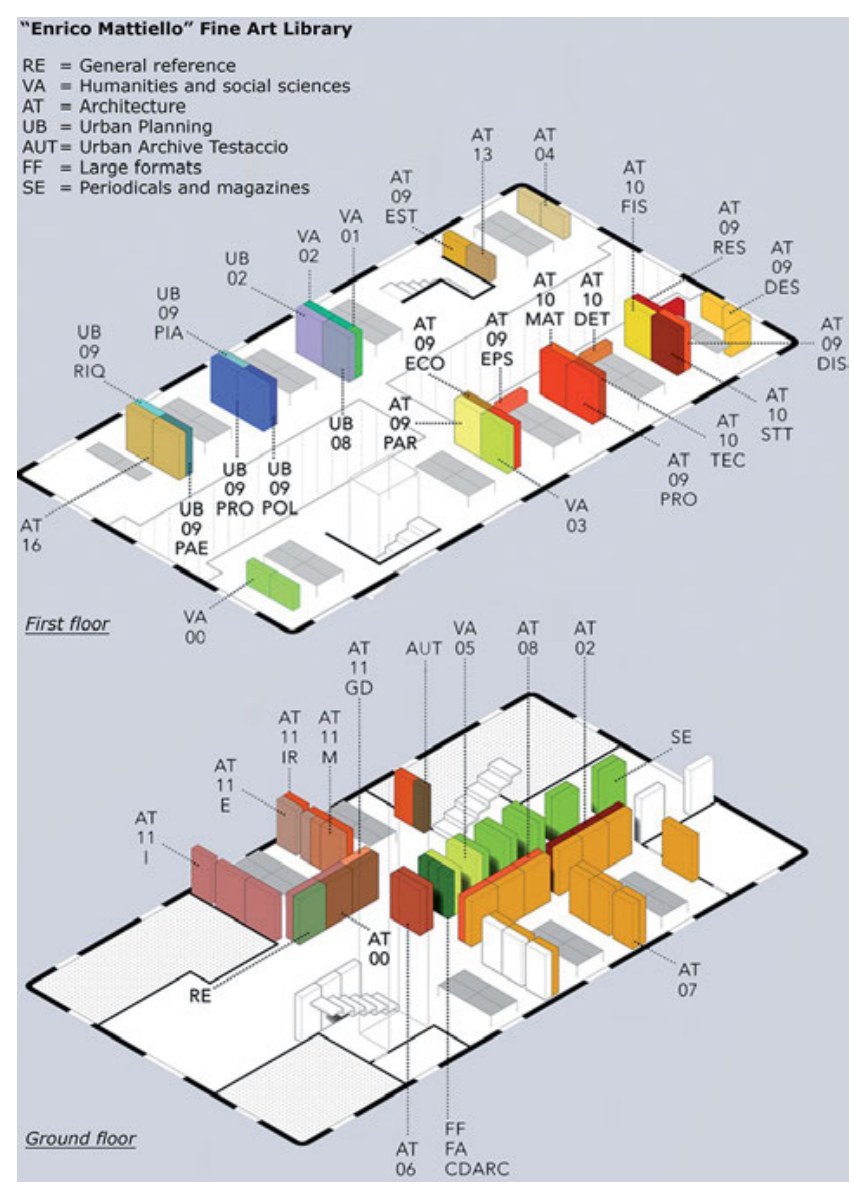

Fig. 12: Enrico Mattiello thematic classification scheme. (c) University Roma Tre.

\section{Conclusion}

After carrying out safety checks on the building in 2010, the project was validated in 2011. For financial reasons, construction was delayed and did not commence until October 2015, concluding in October 2017, for a total cost of approximately $€ 2,000,000$. Today Pavilion 9E has been successfully renovated to accommodate the Enrico Mattiello Architecture Section of the Fine Arts Library at Roma Tre University. 


\section{References}

Clark, Malcolm. 2013. "The Roma3 Faculty of Architecture in the Old Slaughterhouse: A Balance between Intervention and Conservation in the Conversion Designed by Insula." Archilovers, September 23, 2013. https://www.archilovers.com/stories/3860/the-roma3faculty-of-architecture-in-the-old-slaughterhouse.html

Cremona, Alessandro, Claudio Crescentini, Massimo Pentiricci, and Eleonora Ronchetti, eds. 2014. Gioacchino Ersoch, Architetto Comunale: Progetti e Disegni per Roma Capitale d'Italia. Roma: Palombi.

Cupelloni, Luciano. 2002. Il Mattatoio di Testaccio a Roma: Metodi e Strumenti per la Riqualificazione del Patrimonio Architettonico. Roma: Gangemi. 